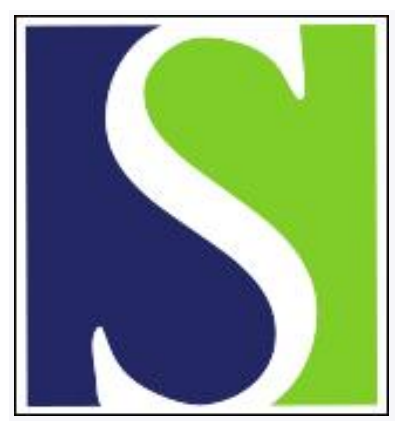

Scand J Work Environ Health 2011;37(6):547-550

https://doi.org/10.5271/sjweh.3170

Published online: 26 May 2011, Issue date: Nov 2011

Effect of brief daily exercise on headache among adults secondary analysis of a randomized controlled trial

by Andersen LL, Mortensen OS, Zebis MK, Jensen RH, Poulsen OM

Affiliation: National Research Centre for the Working Environment, Lersø Parkallé 105, DK-2100 Copenhagen $\varnothing$, Denmark. Ila@arbejdsmiljoforskning.dk

The following articles refer to this text: 2012;38(2):182;

2012;38(2):183-184; 2014;40(3):244-251

Key terms: exercise; headache; physical exercise; randomized controlled trial; RCT; rehabilitation; secondary analysis; tension headache; workplace intervention

This article in PubMed: www.ncbi.nlm.nih.gov/pubmed/21617837 


\title{
Effect of brief daily exercise on headache among adults - secondary analysis of a randomized controlled trial
}

\author{
by Lars L Andersen, PhD, ${ }^{1}$ Ole S Mortensen, PhD, ${ }^{1,2}$ Mette K Zebis, PhD, ${ }^{1}$ Rigmor H Jensen, DrMedSci, ${ }^{3}$ \\ Otto M Poulsen, DrMedSci ${ }^{1}$
}

\begin{abstract}
Andersen LL, Mortensen OS, Zebis MK, Jensen RH, Poulsen OM. Effect of brief daily exercise on headache among adults - secondary analysis of a randomized controlled trial. Scand J Work Environ Health. 2011;37(6):547-550. doi:10.5271/sjweh.3170
\end{abstract}

Objective This paper investigates secondary outcomes (headache) in a randomized controlled trial with physical exercise among office workers with neck/shoulder pain.

Methods A total of 198 office workers with frequent neck/shoulder pain were randomly allocated to either one of two intervention groups ( 10 weeks of resistance training with elastic tubing for 2 or 12 minutes per day, 5 times a week) or the control group, which received weekly health information. Secondary outcomes included changes in frequency, intensity, and duration of headache after ten weeks.

Results Compared with the control group, headache frequency decreased in the 2- and 12-minute intervention groups [0.64 days/week ( $95 \%$ confidence interval [ $95 \% \mathrm{CI}]) 0.23-1.0)$ and 0.79 days/week $(95 \%$ CI $0.37-1.2)$, corresponding to a $43 \%$ and $56 \%$ decrease from baseline, respectively]. Intensity and duration of the remaining headaches were unaffected.

Conclusions Two minutes of daily resistance training for ten weeks reduces headache frequency among office workers with neck/shoulder pain. The vast number of adult workers suffering from one or two days of weekly headaches and who could potentially comply with and benefit from brief exercise programs stresses the applicability of our findings.

Key terms physical exercise; RCT; rehabilitation; tension headache; workplace intervention.

The annual prevalence of headache among adults is $47 \%$ for headache in general, $38 \%$ for tension-type headache, $10 \%$ for migraine, and $3 \%$ for chronic headache (1). Due to its high prevalence, tension-type headache is especially a burden to society in terms of sickness absence and work disability (2). Individuals with musculoskeletal pain experience a four-fold higher prevalence of headache, and those with neck pain are more likely to suffer from headache than those experiencing pain in other restricted areas (3).

Among patients with severe tension-type headache, physical exercise therapies are more effective than massage or acupuncture, but evidence is scarce for the efficacy of such treatment in reducing frequency, intensity, and duration of headache (4-7). In a randomized controlled trial, low-intensity exercises focusing on cervicoscapular muscle-control, reduced the frequency and intensity of cervicogenic headache (8). In another randomized controlled trial, a comprehensive multimodal treatment program of one year - with special emphasis on neck/ shoulder resistance exercises - effectively reduced headache intensity among patients with chronic neck pain (9). However, such comprehensive clinical treatments may not in practice be an available resource at workplaces.

This study investigates - in a secondary analysis of headache in a RCT - the effectiveness of small daily amounts of resistance training for relieving headache among office workers with neck/shoulder pain.

1 National Research Centre for the Working Environment, Copenhagen Ø, Denmark.

2 Department of Occupational and Environmental Medicine, Bispebjerg University Hospital, Copenhagen, Denmark.

3 Danish Headache Center, Department of Neurology, University of Copenhagen, Glostrup Hospital, Glostrup, Denmark.

Correspondence to: Lars L Andersen, National Research Centre for the Working Environment, Lersø Parkallé 105, DK-2100 Copenhagen Ø, Denmark. [E-mail: 1la@arbejdsmiljoforskning.dk] 


\section{Methods}

\section{Study design and flow of participants}

We performed a randomized controlled trial in Copenhagen, Denmark from August-December 2009 and have previously described the study design and reported the primary outcome on neck/shoulder pain (10). From a screening questionnaire and subsequent clinical examination, 198 eligible office workers with frequent neck/ shoulder pain, but without traumatic injuries or serious chronic disease, were randomly allocated to the three intervention groups. Study personnel (investigators and clinical examiners) were blinded to treatment allocation, and participants were instructed not to reveal their particular intervention during follow-up examination. Table 1 shows the baseline characteristics of the participants.

Participants were informed about the study, which conformed to the Helsinki Declaration and was approved by the Local Ethical Committee (HC2008103), and gave written informed consent.

\section{Interventions}

This study has three arms: 2 or 12 minutes of progressive neck/shoulder resistance training with elastic resistance tubing (Thera-Band, Hygenic Corporation, Akron, Ohio, USA), performed 5 times a week at the workplace, and a control group receiving weekly information on general health. All three interventions were initiated simultaneously and lasted 10 weeks.

\section{Secondary outcomes}

Prior to the study, we sent an e-mail-based screening questionnaire asking about the frequency of headache: "How many days have you had headache during the previous month?" with the categories $0,1-3,4-7,8-14$, or $>14$ days. The primary type of headache was determined by the question "Which type of headache do you experience most often?" with the categories "migraine", "tension-type headache", or "don't know" (table 1).

At baseline and once a week throughout the 10-week intervention, participants replied to an internet-based questionnaire on frequency and intensity of headache during the previous week. Frequency of headache was determined by the question "How many days have you had headache during the previous week?"using an 8-point scale from 0-7 days. Intensity of headache was determined by the question "On average, how bad were your headaches when you experienced them during the previous week? where 0 is no pain and 10 is worst imaginable pain" using an 21-point numerical rating scale (NRS) from 0-10 (ie, $0,0.5,1.0, \ldots 9.5,10)$. The rating scale was horizontally oriented to represent a modified visual-analogue scale.
Duration of headache was determined at baseline and follow-up by the question "How long have your headaches typically lasted during the previous month?" with the categories $<1$ hour, $1-8$ hours, $>8$ hours, or all day. Subsequently, $<1$ hour was recoded to 0.5 hour, $1-8$ hours to 4.5 hours, $>8$ hours to 12 hours, and all day to 16 hours. Use of analgesics in relation to headache was determined by the question "How many days have you used painkillers for your headache during the previous month?" with the categories $0,1-3,4-7,8-14$, or $>14$ days. For subsequent analysis, 1-3 days were recoded to 2 days, 4-7 days to 5.5 days, $8-14$ days to 11 days, and $>14$ days to 21 days.

\section{Statistical analysis}

Headache variables were analyzed in accordance with the intention-to-treat principle. Between-group differences were determined by analysis of variance using the Genmod procedure of SAS, version 9.2 (SAS institute, Cary, NC, USA). An alpha level of 5\% was accepted as statistically significant.

\section{Results}

Table 1 shows that at baseline the participants of the three groups were matched for demographic and clinical characteristics. Only 6 of the 198 participants were lost to follow-up.

There was a significant group-by-time interaction for frequency of headache $(\mathrm{P}<0.001)$. Intensity and duration of the remaining headaches and use of analgesics remained unchanged. Table 2 summarizes these results.

We also tested the statistical model with gender, age, and type of headache as covariates, but these were not significant factors.

\section{Discussion}

Our study shows decreased frequency of headache among office workers with neck/shoulder pain in response to small daily amounts of resistance training.

In line with the baseline questionnaire replies, epidemiological studies confirm that tension-type headache is the most prevalent type of headache disorder (11). Our population had a higher prevalence of tension-type headache than the general population (1), which is in agreement with epidemiological observations of higher prevalence of headache among adults with neck pain (3).

Few randomized controlled trials have investigated the effect of exercise on headache specifically in relation to neck pain $(8,9)$. Although the comprehensive 
Table 1. Baseline characteristics of the three intervention groups. Values are group mean and standard deviation (SD) or percentage of participants. There were no significant differences between the groups.

\begin{tabular}{|c|c|c|c|c|c|c|c|c|c|}
\hline & \multicolumn{3}{|c|}{ 2-minute training } & \multicolumn{3}{|c|}{ 12-minute training } & \multicolumn{3}{|c|}{ Control } \\
\hline & Mean & SD & $\%$ & Mean & SD & $\%$ & Mean & SD & $\%$ \\
\hline \multicolumn{10}{|l|}{ Demographics } \\
\hline Age (years) & 44 & 11 & & 42 & 11 & & 43 & 10 & \\
\hline Height (cm) & 171 & 8 & & 170 & 8 & & 169 & 7 & \\
\hline Weight (kg) & 72 & 14 & & 68 & 15 & & 67 & 11 & \\
\hline Body mass index $\left(\mathrm{kg} / \mathrm{m}^{2}\right)$ & 25 & 5 & & 24 & 5 & & 23 & 4 & \\
\hline Women & & & 88 & & & 88 & & & 88 \\
\hline \multicolumn{10}{|l|}{ Clinical variables } \\
\hline \multicolumn{10}{|c|}{ Days with headache during previous month } \\
\hline 0 days & & & 8 & & & 15 & & & 15 \\
\hline $1-3$ days & & & 45 & & & 39 & & & 48 \\
\hline $4-7$ days & & & 30 & & & 27 & & & 28 \\
\hline 8-14 days & & & 9 & & & 12 & & & 5 \\
\hline$>14$ days & & & 8 & & & 6 & & & 3 \\
\hline \multicolumn{10}{|l|}{ Self-reported type of headache } \\
\hline Tension-type headache & & & 80 & & & 82 & & & 80 \\
\hline Migraine & & & 5 & & & 2 & & & 5 \\
\hline Unknown & & & 15 & & & 16 & & & 15 \\
\hline Systolic blood pressure (mmHg) & 127 & 14 & & 124 & 12 & & 126 & 13 & \\
\hline Diastolic blood pressure $(\mathrm{mmHg})$ & 84 & 10 & & 83 & 9 & & 84 & 9 & \\
\hline \multicolumn{10}{|l|}{ Work-related variables } \\
\hline Computer use (\% of worktime) & 93 & 14 & & 96 & 10 & & 91 & 16 & \\
\hline Weekly working hours & 39 & 5 & & 38 & 5 & & 37 & 3 & \\
\hline Duration of office work (years) & 11 & 9 & & 10 & 10 & & 13 & 11 & \\
\hline Higher education & & & 92 & & & 85 & & & 89 \\
\hline \multicolumn{10}{|l|}{ Other variables } \\
\hline Smokers & & & 10 & & & 13 & & & 5 \\
\hline Living with a partner & & & 79 & & & 72 & & & 75 \\
\hline
\end{tabular}

interventions in these studies yielded positive treatment effects, multimodal therapies requiring supervision by an experienced therapist are difficult to implement in a work-setting environment. An alternative could be resistance training at the workplace, which has been shown to decrease neck/shoulder pain (12-15). The present study shows a positive way forward by documenting positive effects on headache of small daily amounts of resistance training at the workplace with minimal need for trainingsupervision (ie, only one introductory session).

While frequency of headache decreased in our study, the intensity and duration of the remaining headaches as well as use of analgesics remained unchanged. Torelli and coworkers reported similar findings among patients with chronic or episodic tension-type headache undergoing traditional physiotherapy (5). In that study, frequency of headache was significantly reduced from 4 to 3 days per week, but the severity and duration of headaches as well as use of analgesics were unchanged. The mean headache frequency of 1.4 days per week at baseline in our population is quite low compared with a clinical headache patient population. However, the vast number of otherwise healthy adult workers suffering from one or two days of weekly headaches, who can potentially comply with and benefit from brief exercise programs, stresses the applicability of our findings.

A limitation of our study is self-reporting of headache type as opposed to using the $2^{\text {nd }}$ edition of the International Headache Classification (ICHD-II) diagnostic headache criteria. A fairly high percentage reported headache of unknown type, probably representing undiagnosed migraines or co-existing tension-type headache and mild migraines. Thus, a detailed diagnostic headache interview and/or validated questionnaire screening migraine would have been valuable.

In conclusion, as little as two minutes of daily resistance training reduces the frequency of headache among office workers with neck/shoulder pain.

\section{Acknowledgements}

The Danish Rheumatism Association provided a grant (R68-A993) for this study and the Hygenic Corporation (USA) provided elastic tubing but no monetary funding. 
Table 2. Baseline values of the headache variables as well as changes after 10 weeks in the control group, the 2-minute versus control group, and the 12-minute versus control group. [SD=standard deviation; $95 \% \mathrm{Cl}=95 \%$ confidence interval.]

\begin{tabular}{|c|c|c|c|c|c|c|c|c|c|c|c|c|}
\hline \multirow[t]{3}{*}{ Variable $^{a}$} & \multicolumn{6}{|c|}{ Baseline } & \multicolumn{6}{|c|}{ Change after 10 weeks } \\
\hline & \multicolumn{2}{|c|}{$\begin{array}{l}\text { 2-minute } \\
\text { training }\end{array}$} & \multicolumn{2}{|c|}{$\begin{array}{l}\text { 12-minute } \\
\text { training }\end{array}$} & \multicolumn{2}{|c|}{ Control } & \multicolumn{2}{|r|}{ Control } & \multicolumn{2}{|c|}{$\begin{array}{l}\text { 2-minute training } \\
\text { versus control }\end{array}$} & \multicolumn{2}{|c|}{$\begin{array}{l}\text { 12-minute training } \\
\text { versus control }\end{array}$} \\
\hline & Mean & SD & Mean & SD & Mean & $\mathrm{SD}$ & Mean & $95 \% \mathrm{Cl}$ & Mean & $95 \% \mathrm{Cl}$ & Mean & $95 \% \mathrm{Cl}$ \\
\hline $\begin{array}{l}\text { Frequency of headache } \\
\text { (days/week) }\end{array}$ & 1.5 & 1.1 & 1.4 & 1.2 & 1.3 & 1.2 & 0.06 & $-0.23-0.15$ & -0.64 & $-1.0--0.23 b$ & -0.79 & $-1.2--0.37^{c}$ \\
\hline Intensity of headache $(0-10)$ & 3.8 & 1.5 & 4.2 & 1.7 & 3.6 & 1.4 & -0.18 & $-0.61-0.24$ & -0.42 & $-1.0-0.18$ & -0.05 & $-0.70-0.61$ \\
\hline Duration of headache (hours) & 6.4 & 4.9 & 5.8 & 4.2 & 5.5 & 4.0 & 0.80 & $-0.29-1.9$ & -1.08 & $-2.5-0.33$ & -0.78 & $-2.2-0.63$ \\
\hline $\begin{array}{l}\text { Use of analgesics for headache } \\
\text { (days/month) }\end{array}$ & 2.7 & 3.8 & 2.6 & 4.3 & 2.2 & 3.3 & -0.23 & $-1.1-0.62$ & 0.15 & $-0.9-1.2$ & -0.50 & $-1.6-0.56$ \\
\hline
\end{tabular}

a Frequency of headache includes all participants and for the remaining variables only those who replied to have at least one day with headache during the last week (intensity) or month (duration and use of analgesics).

b $P<0.01$ significant changes in response to the intervention compared with the control group

c $P<0.001$ significant changes in response to the intervention compared with the control group.

\section{References}

1. Jensen R, Stovner LJ. Epidemiology and comorbidity of headache. Lancet Neurol. 2008 Apr;7(4):354-61. doi:10.1016/ S1474-4422(08)70062-0

2. Schwartz BS, Stewart WF, Lipton RB. Lost workdays and decreased work effectiveness associated with headache in the workplace. J Occup Environ Med. 1997 Apr;39(4):320-7. http://dx.doi.org/10.1097/00043764-199704000-00009

3. Hagen K, Einarsen C, Zwart JA, Svebak S, Bovim G. The co-occurrence of headache and musculoskeletal symptoms amongst 51050 adults in Norway. Eur J Neurol. 2002 Sep;9(5):527-33. doi:10.1046/j.1468-1331.2002.00451.x

4. Biondi DM. Physical treatments for headache: a structured review. Headache. 2005 Jun;45(6):738-46. doi:10.1111/ j.1526-4610.2005.05141.x

5. Torelli P, Jensen R, Olesen J. Physiotherapy for tension-type headache: a controlled study. Cephalalgia. 2004 Jan;24(1):29 36. doi:10.1111/j.1468-2982.2004.00633.x

6. Bronfort G, Nilsson N, Haas M, Evans R, Goldsmith CH, Assendelft WJ, et al. Non-invasive physical treatments for chronic/recurrent headache. Cochrane Database Syst Rev. 2004;(3):CD001878.

7. Sjogren T, Nissinen KJ, Jarvenpaa SK, Ojanen MT, Vanharanta $\mathrm{H}$, Malkia EA. Effects of a workplace physical exercise intervention on the intensity of headache and neck and shoulder symptoms and upper extremity muscular strength of office workers: a cluster randomized controlled crossover trial. Pain. 2005 Jul;116(1-2):119-28. doi:10.1016/j. pain.2005.03.031

8. Jull G, Trott P, Potter H, Zito G, Niere K, Shirley D, et al. A randomized controlled trial of exercise and manipulative therapy for cervicogenic headache. Spine (Phila Pa 1976.) 2002 Sep 1;27(17):1835-43.
9. Ylinen J, Nikander R, Nykanen M, Kautiainen H, Hakkinen A. Effect of neck exercises on cervicogenic headache: a randomized controlled trial. J Rehabil Med. 2010 Apr;42(4):344-9.

10. Andersen LL, Saervoll CA, Mortensen OS, Poulsen OM, Hannerz H, Zebis MK. Effectiveness of small daily amounts of progressive resistance training for frequent neck/shoulder pain: randomised controlled trial. Pain. 2011;152(2):440-6. doi:10.1016/j.pain.2010.11.016

11. Stovner LJ, Zwart JA, Hagen K, Terwindt GM, Pascual J. Epidemiology of headache in Europe. Eur J Neurol. 2006 Apr;13(4):333-45. doi:10.1111/j.1468-1331.2006.01184.x

12. Waling K, Sundelin G, Ahlgren C, Jarvholm B. Perceived pain before and after three exercise programs--a controlled clinical trial of women with work-related trapezius myalgia. Pain. 2000 Mar;85(1-2):201-7. doi:10.1016/S0304-3959(99)00265-1

13. Ylinen J, Takala EP, Nykanen M, Hakkinen A, Malkia E, Pohjolainen T, et al. Active neck muscle training in the treatment of chronic neck pain in women: a randomized controlled trial. JAMA. 2003 May 21;289(19):2509-16. doi:10.1001/jama.289.19.2509

14. Andersen LL, Kjaer M, Sogaard K, Hansen L, Kryger AI, Sjogaard G. Effect of two contrasting types of physical exercise on chronic neck muscle pain. Arthritis Rheum. 2008 Jan 15;59(1):84-91. doi:10.1002/art.23256

15. Andersen LL, Jorgensen MB, Blangsted AK, Pedersen MT, Hansen EA, Sjogaard G. A Randomized Controlled Intervention Trial to Relieve and Prevent Neck/Shoulder Pain. Med Sci Sports Exerc. 2008 May 2;40(6):983-90. doi:10.1249/MSS.0b013e3181676640

Received for publication 8 March 2011 